\title{
A COMUNICAÇÃO DO CASAL E O BEM-ESTAR SEXUAL
}

\author{
Vitória Menezes ${ }^{1}$
}

\section{COUPLE'S COMMUNICATION AND SEXUAL WELL BEING}

\begin{abstract}
Resumo: $\mathrm{O}$ presente texto comenta as transformações que a comunicação vem sofrendo nos dias de hoje. Mesmo dispondo fisicamente de sofisticados equipamentos, a comunicação, principalmente entre os pares, vem encontrando dificuldade em ser estabelecida. A "pressa" e a falta de "treino social" parecem ter papel fundamental neste fenômeno, assim como a "terceirização" do prazer. Mesmo conseguindo disfarçar a dificuldade em vários âmbitos da vida, é na área da sexualidade que a dificuldade encontra maior reflexo, como se constata no set psicológico.
\end{abstract}

Palavras-chave: Terceirização/Prazer; comunicação; sexualidade; psicoterapia sexual; inadequação sexual.

Abstract: This paper comments the transformations that communication is suffering nowadays. Even disposing of physical sophisticated equipments, communication, mainly among partners, has many difficulties to occur. "Speedness" and inefficacy of "social training" seems to play an important role on this phenomenon, as well as pleasure outsourced. Although one can dissemble the difficulties on many ambits of life, it is on sexual area that the difficulty has the major reflex, as one configure on psychological set.

Keywords: Outsource/Pleasure; communication; sexuality; sexual psychotherapy; sexual inadequacy.

Psicóloga, graduada pela UFPE. Pós-graduada em Educação Sexual pelo CEUB/CESEX. Pósgraduada em Psicologia da Família e Realidade Social pela FAFIRE. Especialista em Sexologia Clínica pela FLASSES. e.mail: vitmenezes@terra.com.br 


\section{Introdução}

Comunicar-se parece ser uma preocupação do ser humano, provavelmente impulsionado pela característica de se tratar de um "ser social".

Para que haja comunicação, é necessário que tenha havido a transmissão de uma mensagem.

Sant'Anna acredita ser a comunicação, não apenas fundamental, mas também vital. $\mathrm{O}$ autor defende seu ponto de vista salientando que, a comunicação

[...] é fundamental, na medida em que toda sociedade humana - da primitiva à moderna - baseia-se na capacidade do homem de transmitir suas intenções, desejos, sentimentos, conhecimentos e experiências de pessoa para pessoa. É vital, na medida em que a habilidade de comunicar-se aumenta as chances de sobrevivência do indivíduo, enquanto sua falta é considerada uma séria forma de patologia (SANT'ANNA, 2002, p.2).

Assim, compreender como a comunicação se processa é compreender as relações humanas.

\section{A comunicação do casal}

Seu primeiro ato já é uma comunicação: o choro, ainda que involuntário, traz alegria à parturiente, tranqüilidade à equipe médica e renova as esperanças do mundo.

Uma fogueira foi a forma de comunicação buscada por Isabel, para avisar sua prima, Maria, que o nascimento de João estava próximo.

O cinema eternizou o grito de Tarzan das telas, na memória de geraçōes.

No reino Animal, também há comunicação até entre os animais e os homens. É através do burrico que o homem do sertão, longe dos relógios sofisticados, confirma o passar das horas, e até tem previsão do tempo.

Os sinos foram, durante muito tempo, o meio mais eficiente para anunciar alegrias e dores. A sineta "perversa" das escolas avisou, durante anos, que a austeridade da diretora exigia novo comportamento no pátio! Também foi um apito que conduziu nossos trabalhadores aos galpões das fábricas, usinas e construções e, de quebra, ainda fornecia, também aos vizinhos, a hora certa. Os clarins ainda "tocam" na cidade de Olinda "chamando atenção" para mais um bloco em suas ladeiras. 
Hoje, já não se precisa mais recorrer a uma telefonista, em casa ou na própria loja da telefonia, enfrentando filas insuportáveis, ruídos intermináveis, para se obter uma ligação telefônica. A engenharia das telecomunicações promove encontros, nos permite falar, ver ou conversar com quem quisermos. É como se o outro "estivesse na esquina! Os "aparelhos celulares” não só falam, como filmam e fotografam. Trazem jogos, agenda, calendário, etc., etc., artifícios jamais imaginados, e até mesmo, talvez, dispensáveis, por muitos daqueles que precisaram um dia recorrer a um vizinho, um estabelecimento comercial para, por meio do velho e fiel aparelho telefônico preto cujo fio praticamente não se enrolava, viabilizar uma comunicação.

A internet já nos põe em contato com o mundo, em poucos dígitos. O Orkut promove a partilha de intimidades com estranhos, as "salas de bate papo" preenchem horas a fio.

Já longe da TV preto e branco com válvulas que precisavam de "esquente", hoje temos a cobertura total de tudo que possa estar acontecendo no bairro e no mundo, em tempo quase que real. A TV por assinatura amplia a diversidade de ofertas.

A câmara fotográfica não requer filmes e "revela” uma realidade impensável!

O Jornal e a revista chegam a nossas mãos, com a velocidade muito maior do que nossa capacidade de, até mesmo, entrar em contato com as suas páginas, pois um novo dado pode ter acontecido, tornando obsoleto seu conteúdo.

Há câmaras em toda parte: no shopping, no elevador, nas calçadas, no hall do prédio e na piscina também. Há câmaras na cozinha, diante do berço da criança, no ônibus. Equipamentos sofisticados revelam não só o sexo do feto, mas também outras características do seu genótipo.

As pesquisas nas eleições já nos privam da surpresa do resultado.

Nossos dados pessoais foram distribuídos, nem se sabe como, aos quatro ventos!

De fato, nos tornamos mais próximo do outro e vulneráveis também!

Não há o que questionar sobre a capacidade evolutiva dos equipamentos das telecomunicações e de sua qualidade.

Apesar disso, como andam as comunicações interpessoais? Como se utilizam os meios de comunicação disponíveis?

A ausência de assertividade, a falta de linguagem objetiva, de generosidade nas expressões, gera um mal-estar coletivo, quase que bipolar. As "mensagens" 
necessárias para que se processe a informação parecem encontrar muita dificuldade em chegar ao seu destino. Mesmo se servindo de tanta tecnologia, nunca se ouviram tantos "você não entendeu direito, não foi isto que eu quis dizer" e retificação do que foi dito dia anterior, principalmente pelos nossos políticos e dirigentes estatais.

As relações contemporâneas estão carregadas de "pressa”. A família tem hoje as mesmas 24 horas de que seus antecessores dispunham, mas há um fator extremamente agravante - hoje é preciso trabalhar muito mais, não só pelo mercado concorrido, mas também para manter os novos itens que surgiram na planilha orçamentária desta nova família: celular, seguro de carro, de casa e pessoal, ração para cachorro, plano de saúde, TV por assinatura, taxa de tapa-buraco, condomínio, etc.

A geração, que se empolgou com as fantasias de "Perdidos no espaço" e "os Jet Stones”, usufrui hoje de tecnologias inconcebíveis. Mães sem útero e pais sem espermatozóides maduros já vêem seus filhos dando seguimento à continuidade gênica. Vacinas para as mais diversas doenças já fazem parte dos cartões de imunização. São realidade as células-tronco, transfusão de sangue segura, cirurgias em fetos! O câncer já não é sentença de morte. Centenas de passageiros já estão acomodados num único vôo. O subsolo é meio de transporte e os canais subterrâneos também. O petróleo deixou de ser a única forma de fazer o mundo mover-se. Poucos são os desafios que a engenharia, a medicina, a física, a química, entre tantas outras ciências, não conseguiram vencer.

Em meio a tanta tecnologia espetacular, telefone sem fio, microfone sem "pedestal", transmissões que dispensam o famoso carro gerador, impressoras domésticas sem a fita da máquina de datilografar, a comunicação inter-pessoal parece estar entrando em profunda modificação ou até mesmo em extinção.

Para que serve o "fale conosco" oferecido pelo "serviço de atendimento ao cliente", se a resposta não é devolvida ou apenas gravaçôes impessoais são soltas "sua ligação é muito importante para nós"...?

O formal "Bom dia" tomou o lugar do personalizado "como vai?". Parece que perdeu-se a expressão. É difícil encontrarmos cartões em branco nas papelarias. Estes cederam espaço aos cartóes já com mensagens escritas, os quais não param nas prateleiras. O celular traz "modelos de mensagens" como se adivinhassem que seu usuário não sabe escrever. O serviço de telemensagem dispensa seu texto próprio: Solicita apenas que você diga o tema. $\mathrm{O}$ recado será dado por uma fita previamente gravada. O telegrama animado, da mesma forma, auxilia também os "sem texto". 
Já não se ouve como antes e, assim, a fala também entra em extinção, tal como o pensamento e a reflexão. O encontro parece sofrer com isto!

Já é evidente a transformação nas nossas crianças. Sentadas á frente da TV particular, no próprio quarto, dispondo de DVD e de computador, sem interagir com "pessoas de verdade", têm a infância atrofiada e os sentimentos também.

Por que será que as crianças hoje, diferente de seus pais, são prisioneiros das fraldas descartáveis, que tanto prejuízo trazem à natureza, mesmo aos dois ou três anos (ou mais!)? Será que elas não foram estimuladas a sentirem seus esfíncteres, não sabem falar ou são seus pais ou cuidadores que não querem ouví-las?

A música tecno dispensa a palavra. Impede a conversa. Atrai centenas de jovens.

Terceiriza-se hoje o prazer, a vida! Cuidar pessoalmente dos filhos já não é prática tão comum, mesmo nos dias em que não se trabalha. Agora, em função das novas leis trabalhistas, surgiu a figura até da folguista! É comum presenciarmos babás acompanhando crianças, já não de braço, até em momentos de lazer da família - hotéis, parques, festas de aniversários, viagens, etc. Os pais sentam-se, dormem, comem, bebem, distraem-se sem serem importunados por seus filhos.

"Importunados" - acreditam que estão dando o melhor a eles.

"Qualidade" - esquecem que quando há qualidade, desejamos, a seguir, justamente "quantidade". Que qualidade um hotel ou um avião podem oferecer, longe do colo, do papo, da mão, do sorriso dos pais. Com sorte, a babá poderá até suprir esta necessidade, mas o que fará a substituição do registro eterno de ver um filho livrar-se das "rodinhas" da bicicleta, do olhar brilhante no escuro do teatro, da gargalhada no parque, da surpresa ao ver o castelo de areia ser desfeito pela onda? Se pensassem, os pais não abririam mão desta troca. Muitos preferem simplesmente assistir ao crescimento dos filhos.

Hoje, fazemos quase tudo que precisamos ou pensamos que precisamos, apenas "assistindo" ou pagando á distância. Cartôes e serviços on line que o digam! Uma festa, por exemplo: os bufês estão prontos para nos atender, inclusive, via telefone ou catálogo virtual!

Ninguém precisa mais descascar abacaxi. O supermercado já o descascou. Ele também disponibiliza carnes já tratadas, inclusive picadinhas para o próprio strognoff. O feijāo está na lata, a pizza, no freezer; A roupa pronta, no shopping, e a casa de tecidos, sem função, já nem existe mais. O roteiro 
da viagem pode ser o mesmo copiado da revista. Os preparativos dos eventos, que agregavam a família e os amigos, cederam lugar a um outro prazer, o de "poder pagar".

Para onde foi o prazer de dizer "foi feito por mim"?

De fato, a praticidade do momento nos traz muitas vantagens. Sobra tempo para outras coisas mais urgentes. Sobra?

A fantasia parece estar em baixa. São tantos itens "tem que ter", no enxoval do recém nascido, na cozinha, nas festas, nas férias, que de alguma forma nos sentimos por vezes impedidos de pensar. É só repetir. Talvez esteja aí a raiz de tanto estresse.

Fazer uma festa, enrolar docinhos, escolher o tema para a ocasião, levar e pegar os filhos na escola, colocá-los para dormir e despertá-los com massagem de bom dia, cozinhar, trocar resistência de eletrodomésticos, pendurar quadros, costurar, cuidar da casa, lavar o carro, conversar com amigos, familiares e vizinhos, podem não ser tarefas prazerosas universalmente, mas mesmo aqueles que curtem estas e outras tarefas sentem hoje que está cada vez mais inviável praticá-las.

Pode-se abrir mão de todos estes pretensos prazeres, sem revelar o prejuízo. É verdade! Na formatura dos nossos filhos, não se questiona quem os conduziu desde a porta da pré-escola à Faculdade, nem na festa, se você a contratou por telefone ou pessoalmente. $\mathrm{O}$ vestido fica mais charmoso se for da estilista tal, e, mesmo sem querer, somos levados a abrir mão de tais referências em nome da falta de tempo, da praticidade, do comodismo. Em verdade, parece que se tem mais qualidade, porém menos exercício da improvisação, da criatividade, da comunicação, e, o que é mais doloroso, do prazer, da espontaneidade e da alegria.

Sem sombra de dúvida, a tarefa é cumprida. Corresponde ao esperado social.

\section{O bem-estar sexual}

No entanto algumas coisas na prática do consultório de psicologia já são nitidamente sentidas.

$\mathrm{O}$ adulto jovem perdeu muito de sua capacidade de se expressar. Falta-lhe treino social. Alguns se sentem "estranhos". Recorre-se à academia, à escola de dança, aos clubes de serviços etc., para rever sua capacidade perdida de "encontrar" e interagir com seu semelhante. Não foi estimulado, muitas 
vezes na família, a falar, a ouvir, a sentir. O ter sobrepôs-se ao ser. Ele é um desconhecido dentro de casa, na escola, no trabalho e até dele próprio.

E o sexo? Como pode ser a sexualidade de uma pessoa que aprendeu a ser mais um "com pressa”, que tem estreita ligação com o mais avançado modelo I Pod, mas se encabula ao ter que chamar o garçom ? Alguém que não foi treinado a sentir, mas a fazer. Foi levado à busca do ter e não ao amadurecimento do ser. A repetir e não a criar. A chegar primeiro, desde que não houvesse uma variação. Que recebeu uma educação conteudista e não construtivista?

Considerando que o sexo é uma expressão da vida, podemos imaginar então, o porquê de tanta frustração vir ocorrendo nas quatro paredes.

A realidade atual do consultório nos põe diante de um dado novo e preocupante. As tais apregoadas "tarefas" usadas na psicoterapia sexual, deixam muitas vezes de ser executadas, não apenas por resistência, mas por pura falta de tempo. Necessita-se que sejam inovadas, recriadas pelo psicólogo para que possam acontecer na própria sessão, e que estimulem basicamente o treino assertivo. Para muitos casais, a sessão passou a ser um raro momento de poder falar frente a frente de como foi sua semana, e, não raro, dados importantes da dinâmica da família são passados naquele momento: a empregada pediu demissão, convites recebidos, o resultado da visita ao pediatra.

Muitas vezes bem sucedidos profissionais, de fato cansados da jornada do dia a dia, antevendo as poucas horas disponíveis até o toque do despertador que os levará a reiniciar a lida, já pensam duas vezes antes de se dedicar à possibilidade de manter um contato físico. Inibem a fantasia sexual, sabidamente essencial para a vivência saudável da sexualidade. Sem fantasias positivas, fica mais difícil manter-se um coito.

A exemplo do urso Panda, animal em extinção, também estamos com "preguiça” de nos relacionarmos sexualmente. $\mathrm{O}$ erótico lentamente vai saindo das vidas dos casais. Falta-lhes tempo. Engolem-se as palavras. Sobram-lhes fadiga e tarefas urgentes a serem executadas.

As emoções, positivas ou negativas, não combinam com este quadro. Busca-se o "morno".

O outro passa a ser visto não como cúmplice na vida, mas como um simples aliado na jornada.

Como falar agora ao amante do desejo íntimo, dos medos, das certezas, de si próprio enfim, se não houve treino? 
Talvez seja através da disfunção sexual que a mente e o corpo, já agonizantes, buscam derradeiramente expressar que algo anda mal, muito mal. O corpo fala, porém nós não queremos, não sabemos mais ouvi-lo. Hoje, na farmácia ou nas mãos do cirurgião, calamos sem culpa expressōes do corpo: sono, insônia, obesidade, má alimentação, intestinos desregulados e muito mais. Sem maiores esforços, só com um cartão de crédito, cala-se, "corrigi-se"o corpo, pensando que se engana a mente. A comunicação está nitidamente com ruídos.

Até que o sexo - mais uma vez o sexo - nos traia e impeça que a "brincadeira do faz de conta" revele justo o que pretendíamos esconder.

Felizmente, não inventaram pílulas que dispensem a participação de cada um na sua vivência sexual Aqui não há terceirizações. Transa-se com o outro, nunca pelo outro! Podemos enviar, aos queridos, beijos e abraços por $e$ mail, telefonemas, manifestações repletas de sentimentos positivos, de carinho, mas orgasmos ainda não!

O sexo talvez seja hoje o único momento do qual não conseguimos fingir por tempo indeterminado. Podemos esconder o desencontro em festas, falta de disponibilidade afetiva para os filhos com excelentes babás, a desarmonia numa viagem, a dor num carnaval fora de época, enganar, com um celular de última geração que estamos falando e ouvindo. Podemos pedir emprestados prazeres de outros, terceirizar tarefas, mas, felizmente, no sexo, somos de fato primordialmente responsáveis pelo nosso prazer. É no sexo que nos mostramos, despidos, sem fantasias e ao mesmo tempo com todas elas, nosso mais genuíno jeito de nos comunicarmos. Finalmente, há o sexo nas nossas vidas para nos devolver a responsabilidade pela felicidade. E, quem sabe, nos comunicar o caminho do re-nascimento. Mas, quem está interessado em ouvir?

\section{Referências bibliográficas}

SANT’ANNA, A. Propaganda: teoria, técnicas e prática. São Paulo: Pioneira Thomson Learing, 2002.

\section{Bibliografia consultada}

CAVALCANTI, R.; CAVALCANTI, M. Tratamento clínico das inadequações sexuais. 2 ed. São Paulo: Rocca. 1992

HITE, S. Sexo e negócios. Rio de Janeiro: Bertrand Brasil. 2001. 